\title{
De fundamentos y funciones: ¿un puente entre la responsabilidad civil y la responsabilidad del Estado o más argumentos para el divorcio?
}

DOI: http://dx.doi.org/10.15425/2017.511

\begin{abstract}
Resumen
¿Por qué un particular que causa un daño a otro debe responder, y por qué debe hacerlo el Estado si el daño lo causa uno de sus agentes? ¿Qué objetivos debe perseguir un sistema de responsabilidad civil extracontractual? Las preguntas anteriores están relacionadas con los fundamentos y las funciones de la responsabilidad civil. Este artículo estudia las teorías que han sido propuestas para responderlas y luego evalúa su posible extensión a la responsabilidad extracontractual del Estado. Se argumenta que el estudio de los fundamentos y las funciones de la responsabilidad civil es un presupuesto necesario para entender - y cuestionar - sus similitudes y diferencias con el régimen de la responsabilidad del Estado. Y, por qué no, para pensar en su eventual unificación.
\end{abstract}

\section{Palabras clave}

Responsabilidad civil, responsabilidad del Estado, fundamentos, funciones.

\footnotetext{
Abogado summa cum laude de la Universidad de los Andes y especialista en derecho administrativo de la Universidad Externado de Colombia. Es oficial mayor en la Sección Tercera del Consejo de Estado, profesor en la Facultad de Jurisprudencia de la Universidad del Rosario y coordinador del Semillero de Derecho Contractual de la Universidad de los Andes. Fue asociado en Gómez-Pinzón Abogados y profesor auxiliar en la Facultad de Derecho de la Universidad de los Andes. Las posturas expresadas en este artículo son personales y no comprometen a ninguna institución o persona distinta del autor. Orcid: 0000-0003-4300-0011.
} 


\title{
Of foundations and functions: A bridge between private and public tort liability or additional reasons for divorce?
}

\begin{abstract}
Why should an individual who has caused harm pay damages? Why should the government be liable if tort has come from one of its agents? What objectives should be pursued by a legal system of tort liability? These questions are related to the foundations and functions of civil tort liability. This article studies the theories that have been proposed to answer those questions, and then explores if they can be extended to public tort law. It is argued that the study of the foundations and functions of civil tort law is a necessary step in order to understand -and dispute- the similarities and differences between private and public tort law. And, why not, to think about eventually unifying both regimes.
\end{abstract}

\section{Keywords}

Civil tort liability, public tort liability, foundations, functions. 


\section{Introducción $^{1}$}

La responsabilidad civil extracontractual ${ }^{2}$ es una institución del derecho privado con un hondo trasfondo teórico. Para cada asunto hay una discusión y para cada discusión hay innumerables posturas. Entre los debates doctrinales que la rodean, uno que se presenta con relativa frecuencia es el de su extensión normativa - de sus principios, reglas y consecuencias - a la responsabilidad extracontractual del Estado. ¿Puede y debe el Estado responder igual a como lo hacen los particulares? ¿Pueden extrapolarse los debates doctrinales de la responsabilidad civil a su contraparte pública?

No se trata de saber si fue primero el huevo o la gallina. Es claro que, como sistema, la responsabilidad de los particulares precedió a la responsabilidad del Estado y que la segunda fue adquiriendo gradualmente autonomía frente a la primera. Tanto así que, incluso, algunos en la doctrina han entendido que el surgimiento de la responsabilidad del Estado como sistema autónomo era una consecuencia natural de la "evolución" de las comunidades políticas modernas 3 .

Se trata, en cambio, de establecer si puede defenderse dicha autonomía. Como se han preguntado algunos autores, ¿si dos personas sufren el mismo daño, uno causado por un agente del Estado y otro por un particular, las consecuencias -al menos para la víctima-deberían ser las mismas? En Colombia es probable que no lo sean ${ }^{4}$, teniendo en cuenta la multiplicidad de regímenes existentes tanto al interior de la responsabilidad privada y pública, como entre sís. En un sistema

$1 \quad$ El autor agradece a Guillermo Otálora por la atenta dirección del trabajo de grado que dio origen a este artículo, el cual es en buena medida el fruto de sus sugerencias siempre provocadoras y esclarecedoras. A su vez, agradece a Felipe Yamin por sus valiosos comentarios a uno de los borradores de este texto y por ayudarlo a ser una versión un poco menos imperfecta de las siempre imperfectas ideas del autor.

2 En este texto se hará referencia únicamente a la responsabilidad de tipo extracontractual. Así, cuando se hable de responsabilidad civil se estará haciendo referencia exclusivamente a responsabilidad extracontractual de los particulares, y cuando se mencione la responsabilidad del Estado o responsabilidad pública se tratará de la responsabilidad extracontractual del Estado.

3 Eduardo García de Enterría y Tomás Fernández Rodríguez, Curso de derecho administrativo, tomo II (Madrid: Thomson-Civitas, 2004), 357-373. Ramiro Saavedra Becerra, De la responsabilidad patrimonial del Estado, tomo I (Bogotá: Ibáñez, 2018), 61-117. Óscar Álvaro Cuadros, Responsabilidad del Estado: fundamentos, aplicaciones, evolución jurisprudencial (Buenos Aires: Abeledo-Perrot, 2008). Yolanda Margaux y Ciro Guecha, "La responsabilidad del Estado, una obligación de indemnizar perjuicios”, Revista Diálogos de Saberes, n. 25 (2006): 193-210.

$4 \quad$ Luis Felipe Botero Aristizábal, "El concepto de daño”, en Derecho de las obligaciones, tomo III, coordinado por Marcela Castro de Cifuentes (Bogotá: Temis; Universidad de los Andes, 2018), 66.

5 En la responsabilidad privada, la asunción de un daño por parte de una persona diferente de la víctima dependerá de si la responsabilidad es directa o indirecta y si el agente actuó con dolo, con culpa 
podría estarse ante responsabilidad subjetiva y en el otro objetiva. En el uno el daño podría ser "antijurídico" y en el otro no. En el uno la reparación podría incluir ciertos perjuicios y en el otro no incluirlos.

Este problema podría intentar resolverse a partir de algunas instituciones de la responsabilidad -el "principio de reparación integral", la "antijuridicidad del daño", la máxima alterum non laedere-. Sin embargo, nuevamente haría falta preguntarse por qué aquellas instituciones son exclusivas de alguno de los dos regímenes o comunes a ambos.

En consecuencia, este artículo propone dar un paso atrás. Se advierte de una vez que no se intentará resolver si la responsabilidad civil y la responsabilidad del Estado deberían unificarse en Colombia. En cambio, se propondrá un insumo que puede ser determinante para encuadrar dicha pregunta y, a partir de ahí, responderla. Ese insumo previo son los fundamentos y las funciones de la responsabilidad civil como sistema general.

Cuando se hace referencia a los fundamentos de la responsabilidad civil, de lo que se está hablando es de las razones que se pueden proponer para justificar la existencia y configuración especial de un sistema como este. ¿Por qué cuando un particular causa un daño debe responder, y por qué debe hacerlo el Estado si el daño es causado por uno de sus agentes? Por su parte, cuando se habla de las funciones, la pregunta recae sobre las tareas que un sistema de responsabilidad cumple o debe acometer. ¿Para qué sirve? ¿Qué objetivos debería perseguir y qué consecuencias obtener? ${ }^{6}$

Así las cosas, este artículo comienza con una recapitulación de las principales teorías que se han propuesto en la doctrina sobre los fundamentos de la responsabilidad civil extracontractual, para luego pasar a explorar sus funciones.

o sin ellas, entre otras variables. En la responsabilidad estatal, puede depender de si se produjo una falla del servicio, un riesgo excepcional o un daño especial, aunque algunos sostienen que el concepto de daño antijurídico subsumió los llamados títulos de imputación, y ahora por lo tanto solo se exige que el daño sea particular y grave. Véase Consejo de Estado, Sala de lo Contencioso Administrativo, Sección Tercera. Aclaraciones de voto del magistrado Martín Bermúdez Muñoz a las sentencias del 18 de julio del 2019 (Exp. 44572) y 20 de noviembre del 2020 (2013-00216 AG).

En discusiones como esta es frecuente reclamar que se aclare si la postura a adoptar es normativa o descriptiva. Consideramos, de la mano con Dworkin, que esta distinción no es del todo útil. En efecto, toda descripción de una práctica social involucra la impresión de un contenido valorativo, pues implica elegir qué categorías la encuadran, qué es relevante y qué no. Es más importante considerar cuál es el propósito de la interpretación. En este sentido, la tarea acometida en este artículo involucra un componente valorativo, en tanto que se sugiere cuál es el panorama, cómo puede comprenderse de manera adecuada y en dónde existen dificultades argumentativas. Además, se propone un entendimiento particular de las instituciones analizadas. Bien decía Dworkin que interpretar sin incluir ningún contenido valorativo "es como un hombre en el Polo Norte a quien le dicen que puede ir a donde quiera, excepto hacia el sur". Ronald Dworkin, El imperio de la justicia, traducido por Claudia Ferrari (Barcelona: Gedisa, 2008), 60. 
Si queremos determinar hasta qué punto deben regularse por igual los daños causados por un particular y por un agente estatal, primero hay que preguntarse por qué es necesario que el aparato jurisdiccional responda ante los daños y para qué lo hace de determinada forma. Luego de esta recapitulación se explorará cómo el estudio de los fundamentos y las funciones de la responsabilidad de los particulares puede extenderse (o no) a la responsabilidad del Estado.

Como resultado de este análisis, se sostendrá que los fundamentos y las funciones de la responsabilidad de los particulares sí pueden extrapolarse a la responsabilidad del Estado. En particular, se argumentará que la construcción teórica de la responsabilidad civil permite explicar la responsabilidad estatal como una - de varias - formas de control del poder público. En efecto, los fundamentos y las funciones de la responsabilidad civil son útiles para entender el vínculo jurídico que se establece entre víctima y responsable, que es distinto de otras formas de intervenir en la actividad de la administración, y que no se aleja significativamente de los principios que orientan la responsabilidad de los particulares.

\section{Las teorías sobre los fundamentos de la responsabilidad civil}

Siguiendo con la estructura propuesta para este artículo, a continuación, se planteará una breve recapitulación de las principales teorías que se han expuesto para justificar la existencia y configuración de un sistema de responsabilidad civil (sus fundamentos), para luego explicar las tareas que debería perseguir dicho sistema una vez establecido (sus funciones).

En la teoría general de la responsabilidad civil pueden identificarse al menos dos corrientes principales sobre cómo entender su justificación: (1) quienes la entienden como una expresión de principios de justicia y (2) quienes la conciben como un instrumento para reducir los costos sociales.

\section{A) La responsabilidad civil como expresión de principios de justicia}

La primera vertiente teórica sobre los fundamentos de la responsabilidad civil entiende que este sistema es un reflejo de principios de justicia superiores. En pocas palabras, el aparato jurisdiccional debe intervenir cuando un particular causa daño a otro - y se cumplen ciertas condiciones adicionales-, porque así lo demanda la 
"Justicia". O, en sentido contrario, porque es injusto que alguien sufra un daño sin que se adopten medidas para reaccionar ante él?.

Dentro de esta vertiente que entiende la responsabilidad civil como expresión de principios de justicia, un grupo mayoritario de teóricos ubican la razón de ser del sistema en la llamada justicia correctiva ${ }^{8}$.

Para entender esta categoría debe acudirse a su origen: la distinción aristotélica entre justicia distributiva y justicia correctiva9 ${ }^{9}$. Por una parte, la justicia distributiva se concentra en la asignación de los recursos, derechos o bienes sociales en proporción al mérito. En otras palabras, por qué es justo o injusto que 'A' tenga más dinero, bienes o derechos que los que corresponden a ' $\mathrm{B}$ '. Por otra parte, la justicia correctiva regula las relaciones bilaterales entre los asociados sobre los bienes sociales que ya han sido asignados. Es decir, se toma como premisa una distribución previa — sin cuestionar si dicha distribución es "justa" o "injusta" — , y se centra la atención en la licitud o ilicitud de su transferencia ${ }^{10}$. La justicia correctiva interviene a partir de un estado de cosas ya configurado previamente.

Piénsese, por ejemplo, en un hurto. La justicia correctiva lo reprocha porque se priva de un bien a su dueño sin tener ninguna justificación, es decir, se está alterando la situación preexistente por fuera de los canales debidos — un canal debido sería, verbigracia, la venta del bien-. Este reproche de la justicia correctiva opera con independencia de si, para la justicia distributiva, era justo que la víctima del hurto fuera la dueña del bien en primer lugar, o si habría sido más justa una distribución en la que - por ejemplo- quien hoy es ladrón fuera el propietario original.

Pues bien, como se adelantó, para varios autores el fundamento de la responsabilidad civil se encuentra en la justicia correctiva. El argumento, a grandes rasgos, iría así: cuando un sujeto causa daño a otro, lo está privando de un bien (inmaterial o material) a pesar de no tener un justo motivo para perjudicarlo. La víctima resulta en una posición desmejorada frente a la que tenía antes, sin que haya hecho nada para merecer ese infortunio. La justicia correctiva demanda, entonces,

$7 \quad$ Nos referimos en este punto a reaccionar y no a reparar porque la reparación, como se verá, es una de las funciones particulares que puede cumplir la responsabilidad civil, en línea con la fundamentación teórica que se adopte. Girona, n. 29 (2010): 8-15. 
como imperativo moral, que se subsane — que se corrija - aquella alteración ilícita de la situación preexistente y se retorne al estado anterior ${ }^{11}$.

A partir de ello, autores como Coleman explican la responsabilidad civil como un conjunto de distintos deberes, todos orientados a satisfacer los imperativos de la justicia correctiva. En efecto, bajo esta teoría los asociados resultan obligados en dos niveles. Por un lado, se imponen unos deberes de primer orden, los cuales prohíben ciertas conductas dañinas. Es decir, determinan qué conductas son consideradas ilícitos civiles o -más ampliamente- hechos generadores de responsabilidad. Por otro lado, existen unos deberes de segundo orden, los cuales aparecen en caso de ruptura de los deberes de primer orden y demandan la reparación de los daños que aquellas transgresiones hayan causado ${ }^{12}$. En un ejemplo: es un deber de primer orden no atropellar a otra persona y, en caso de que así suceda, es un deber de segundo orden corregir las consecuencias que dicho acto haya generado.

Para cerrar este apartado vale la pena resaltar que la corriente teórica que identifica los fundamentos de la responsabilidad civil con principios de justicia no necesariamente se limita a la justicia correctiva. Así, por ejemplo, Papayannis asegura que la responsabilidad civil —además de tener un componente de justicia correctiva - también comprende la justicia distributiva cuando asigna "derechos y deberes de indemnidad"13. Piénsese, por ejemplo, en un sistema de responsabilidad que establece regímenes de responsabilidad subjetiva y objetiva según el perpetrador, la víctima o la actividad: al hacerlo, está regulando determinadas situaciones en las cuales se puede dañar y en otras no, y distribuye, entonces, ciertas cargas sobre daños que deben sufrirse y otros que $n o^{14}$.

\section{B) La responsabilidad civil como instrumento para reducir los costos sociales}

A las teorías que entienden la responsabilidad civil como expresión de principios de justicia se contraponen aquellas que la justifican como un instrumento para reducir

11 Lawrence Rosenthal, "A theory of governmental damages liability: Torts, constitutional torts and takings". University of Pennsylvania Journal of Constitutional Law 9, n. ${ }^{\circ} 3$ (2007): 838.

12 Jules Coleman, Scott Hershovitz y Gabriel Mendlow, "Theories of the common law of torts", en The Stanford Encyclopedia of Philosophy, editado por Edward N. Zalta (2015), sección 3.1.

13 Papayannis, "Teorías de la responsabilidad extracontractual”, 11.

14 En palabras de Díez-Picazo: "Cuando ocurre una desgracia, una calamidad o un accidente del que se siguen daños para las personas o para las cosas, hay que decidir si el que experimenta el daño no tiene otra posibilidad que la resignación (lo sufre él) o si puede esperar algo de los demás y, mejor, si tiene derecho a ello", Luis Díez-Picazo, Derecho de daños (Madrid: Civitas, 1999), 41. 
los costos de vivir en sociedad $-\mathrm{y}$, así, maximizar los beneficios de los asociados-. La principal de estas teorías instrumentales se origina en el llamado análisis económico del derecho (AED).

En términos muy generales, la postura del AED sobre la responsabilidad civil asume que en la vida social existirán daños y que el derecho debe reconocer esta realidad. Así las cosas, la atención debe centrarse en buscar el nivel óptimo de prevención de daños: esto es, aquel en el que los costos totales de la prevención, de la reparación y de la adjudicación de los daños sean los menores ${ }^{15}$. Bajo la visión del AED, la responsabilidad civil se constituye entonces como un sistema de incentivos orientados a garantizar que quienes estén en mejor posición de asumir determinados costos relacionados con la producción de daños los asuman hasta donde sea económicamente razonable ${ }^{16}$. Dependiendo de las circunstancias particulares y la posición de cada sujeto, la responsabilidad civil puede asignar la carga de prevenir el daño, de soportarlo o de repararlo.

Papayannis ilustra este razonamiento de la siguiente manera:

Parece obvio que ningún agente racional invertiría para evitar un daño más de lo que cuesta soportarlo. Si adoptando medidas precautorias a un coste de 10 un individuo puede reducir su daño esperado de 50 a 35, es razonable que tome las medidas, ya que el beneficio que obtiene es superior al gasto que realiza. No es razonable que invierta una suma superior a 15 para evitar ese daño marginal, pero sí lo es que invierta cualquier suma inferior ${ }^{17}$.

Bajo el AED, la responsabilidad civil debe evaluar en qué casos a un individuo le resulta más razonable prevenir un daño (por ejemplo, porque desarrolla permanentemente la actividad y puede prevenirlo con costos bajos); en qué casos un individuo debe soportarlo (por ejemplo, en daños cuyos costos de prevención para cualquiera de los actores serían más altos que la entidad misma del daño); y en qué casos debe asumir el costo de repararlo.

Al final, el criterio que se utiliza para implementar normativamente cada uno de los anteriores supuestos es la combinación que lleve - conjuntamente- a los menores costos totales para enfrentar el manejo de los daños en sociedad. Y de esta manera se justifican y configuran los sistemas de responsabilidad civil bajo el AED. Press, 1970), 24-29.

16 Werner Hirsch, Law and economics. An introductory analysis (San Diego: Academic Press, 1999), 143. 


\section{Las teorías sobre las funciones de la responsabilidad civil}

En paralelo a las preguntas sobre los fundamentos de la responsabilidad civil extracontractual se encuentran las preguntas sobre sus funciones. Si los fundamentos hacen referencia al "por qué" de la responsabilidad civil, las funciones se refieren al "para qué". Según se adelantó, las funciones son las tareas que cumple o debe cumplir un sistema de responsabilidad civil. Naturalmente, la perspectiva que se adopte sobre los fundamentos de la responsabilidad civil tendrá incidencia en las funciones que se le asignen, por lo que a continuación se podrá observar alguna correspondencia entre unas y otras.

La doctrina ha propuesto diversas clasificaciones de las funciones de la responsabilidad civil. En este texto se proponen cuatro categorías para agruparlas: (1) la función reparatoria, (2) la función preventiva, (3) la función sancionatoria y (4) la función distributiva.

\section{A) La función reparatoria}

Por lo general esta función es reconocida en la doctrina y la jurisprudencia como la función central y principal de la responsabilidad civil. Entre varias definiciones doctrinales de reparar nos inclinamos por entenderla como poner a la víctima "en una situación similar a la que tendría si el daño no hubiera ocurrido"18.

La función reparatoria se deriva claramente de la concepción de la responsabilidad civil como una expresión de principios de justicia correctiva. Si, como se explicó, la justicia correctiva se enfoca en las relaciones bilaterales entre los asociados sobre los bienes o derechos ya distribuidos, es entendible que la función principal de la responsabilidad civil sea reaccionar ante un hecho que implique una ruptura indebida de la situación preexistente. Por tanto, mediante la reparación, la responsabilidad civil busca "restablecer la igualdad que ha sido rota" por el daño ${ }^{19}$. Así las cosas, la función reparatoria ilustra la preocupación de un sistema de responsabilidad civil por conjurar, hasta donde sea posible, las consecuencias del daño sobre la víctima: ponerla en la posición que tendría si no lo hubiera sufrido. por el civilmente responsable", IARCE (2015): 1. 
En varios sistemas, incluido el colombiano, la centralidad de la función reparatoria se refleja en el llamado principio de reparación integral, consagrado positivamente en el artículo 16 de la Ley 446 de 1998 y el artículo 283 inciso 4 del C. G. P. ${ }^{20}$. Se puede decir, como definición de este principio, que el daño es el presupuesto y límite de la responsabilidad, así como de la obligación reparatoria que emana de ella. $\mathrm{O}$, como reza la frase atribuida a Toulemon y Moore: "debe repararse el daño, todo el daño y nada más que el daño".

El principio de reparación integral "impone devolver al afectado a la misma situación que se encontraba previo al suceso, tratando de borrar la sombra de lo acontecido (reparación in natura) o de compensar a la víctima mediante el equivalente pecuniario"21. Nada más y nada menos. En esta medida, se dice que el principio de reparación integral es un límite a las otras funciones de la responsabilidad. El responsable solamente debe asumir la reparación que corresponda a la entidad del daño, por lo que el componente sancionatorio, preventivo o distributivo de la responsabilidad deberá ser un mero efecto secundario de la obligación reparatoria, ubicado en todo caso dentro de sus precisos límites ${ }^{22}$.

Como coda de esta sección -y aunque el objetivo de este artículo no es descomponer cada uno de los conceptos que integran las teorías aquí reseñadas-, es difícil resistirse a dejar planteado un cuestionamiento a la visión mayoritaria sobre el contenido y alcance del principio de reparación integral. Se dice que, para reparar, el juez "deberá determinar con exactitud no solo cada una de las lesiones, sino que deberá valorarlas y sumarlas para que pueda hablarse, a ciencia cierta, de una reparación total"23. Pero la reparación no se trata de una simple actividad de valorar y sumar: en particular, si se está ante daños extrapatrimoniales, no resulta posible establecer una equivalencia entre la "entidad" del daño y la "cuantía" de la reparación.

Para resolver este problema, la doctrina y la jurisprudencia han propuesto varias alternativas. Algunos consideran que existen diversas formas de reparación:

20 Ley 446 de 1998, art. 16: "Dentro de cualquier proceso que se surta ante la Administración de Justicia, la valoración de daños irrogados a las personas y a las cosas, atenderá los principios de reparación integral y equidad y observará los criterios técnicos actuariales", C. G. P., art. 283, inc. 4: "En todo proceso jurisdiccional la valoración de daños atenderá los principios de reparación integral y equidad y observará los criterios técnicos actuariales".

21 Diego Sandoval Garrido, "Reparación integral y responsabilidad civil: el concepto de reparación integral y su vigencia en los daños extrapatrimoniales a la persona como garantía de los derechos de las víctimas", Revista de Derecho Privado Universidad Externado de Colombia, n. ${ }^{\circ} 25$ (2013): 240.

23 Felipe Navia Arroyo, "Daño moral, daño fisiológico y daño a la vida de relación en Colombia", Revista de Derecho Privado Universidad Externado de Colombia, n. ${ }^{\circ} 12-13$ (2007): 291. 
la reparación in natura (eliminación real del daño), la indemnización compensatoria (equivalente dinerario) y la recompensa satisfactiva (suma de dinero que no equivale al daño, pero puede proveer otras satisfacciones) ${ }^{24}$. Para otros, el principio de reparación integral no aplica sobre daños inmateriales ${ }^{25}$.

Por su parte, la Sala de Casación Civil de la Corte Suprema de Justicia ha parecido utilizar el principio de reparación integral como un instrumento conveniente para funciones diversas, como reconocer nuevas tipologías de daño extrapatrimonial ${ }^{26}$ y aumentar, reducir o limitar la cuantía de la indemnización de los daños inmateriales ${ }^{27}$. El análisis sobre qué tan persuasivas son estas explicaciones tendrá que ser tema de otro artículo, pero, en todo caso, reflejan el uso maleable y generalizado del principio de reparación integral en la jurisprudencia colombiana.

En fin, no puede desconocerse la importancia que tiene la función reparatoria para entender la responsabilidad civil en la actualidad. Sea o no la única función que se admita, es claro que, en general, con la responsabilidad civil se busca reaccionar a un daño y devolver a la víctima, en la medida de lo posible, al lugar en el que habría estado si esa alteración en sus condiciones preexistentes no se hubiera producido.

\section{B) La función preventiva}

Una segunda función que se suele asociar a la responsabilidad civil es la de "prevenir": evitar que se generen daños en el futuro. Esta función puede ser reconocida a la vez por quienes entienden la responsabilidad civil como expresión de principios

24 Eugenio Llamas Pombo, "Formas de reparación del daño", en Realidades y tendencias del derecho en el siglo XXI, tomo IV (Bogotá: Pontificia Universidad Javeriana, 2010), 75-76.

25 Arturo Solarte Rodríguez, "El principio de reparación integral del daño en el derecho contemporáneo", en Tendencias de responsabilidad civil en el siglo XXI (Bogotá: Pontificia Universidad Javeriana, 2009), 139.

26 Las tres categorías de daños extrapatrimoniales que reconoce hoy la jurisprudencia de la Sala de Casación Civil de la Corte Suprema de Justicia — daño moral, daño a la vida de relación y daños a bienes personalísimos de especial protección constitucional- han sido adoptadas por vía jurisprudencial bajo la égida del principio de reparación integral. Véase Corte Suprema de Justicia, Sala de Casación Civil. Sentencias de 21 de julio de 1922 (G.J. XXIX, n. ${ }^{\circ} 1515$ ); 22 de agosto de 1924 (G.J. XXXI, n. ${ }^{\circ}$ 1602); 13 de mayo del 2008 (Rad. 1997-09327-01); 18 de septiembre del 2009 (Rad. 2005-00406-01); 5 de agosto del 2014 (Rad. 2003-00660-01).

A pesar de que el daño extrapatrimonial es, por definición, inestimable, en varias ocasiones se ha utilizado el principio de reparación integral como instrumento para intentar establecer una correspondencia entre la cuantía del perjuicio y la cuantía de la reparación. Véase Corte Suprema de Justicia, Sala de Casación Civil. Sentencias de 25 de noviembre de 1992 (n. ${ }^{\circ}$ C-478); 9 de julio de 2010 (Rad. 1999-02191-01); 9 de diciembre del 2013 (Rad. 2002-00099-01); 17 de noviembre del 2016 (Rad. 2000-00196-01). 
de justicia y por quienes adoptan un enfoque instrumental, aunque suele ser más común entre los segundos.

Por el lado de la justicia correctiva, la función preventiva se explica porque los daños son indeseables: es virtuoso evitar que se produzcan alteraciones injustas de la distribución asignada de los recursos y bienes sociales. En últimas, ¿quién no valoraría tener una garantía de que no va a sufrir daños? El daño mejor reparado, puede decirse, es el que no se produce ${ }^{28}$. Mediante el reconocimiento explícito de una función preventiva de la responsabilidad civil, pueden ampliarse medidas ya existentes -y crear otras nuevas- a través de las cuales los ciudadanos puedan incluso acudir al juez antes de que se produzca un daño ${ }^{29}$.

Ahora bien, desde una óptica de la justicia correctiva la función preventiva encuentra un límite en que el potencial perpetrador no puede terminar privado de un bien o derecho que ha adquirido legítimamente. No sería aceptable, por ejemplo, imponer condenas pecuniarias que excedan la entidad del daño para "escarmentar" al agente de modo que no vuelva a causar daños de ese tipo, porque se estaría creando una nueva desigualdad relacional reprobada por la justicia correctiva. No se le puede quitar más de lo que quitó. Es por ello que algunos sostienen que no es deseable adjudicarle una función preventiva a la responsabilidad civil ${ }^{30}$, y si llega a prevenir lo hará solamente como consecuencia secundaria -y casi fortuita- de la estricta reparación del daño ${ }^{31}$.

Por otro lado, desde una perspectiva instrumental como la que postula el AED es evidente que la función preventiva adquiere un papel central en la responsabilidad civil. Como lo sostiene Calabresi, la responsabilidad civil para el AED debe servir para evitar los costos de los accidentes ${ }^{32}$. Por supuesto que no se previenen todos los daños, sino aquellos que es económicamente razonable evitar. Pero si hay algunos que no se previenen - por ejemplo, porque el costo de prevención sería superior a la entidad del daño-, la responsabilidad en todo caso habrá cumplido con su cometido de conseguir la mayor reducción posible de los costos sociales, y así evitar que se incurra en pérdidas evitables. lidad civil en el siglo XXI y trascendencia de la prevención (Bogotá: Pontificia Universidad Javeriana, 2013), 69-95.

29 Sergio Rojas Quiñones, “Apología del potencial preventivo de la responsabilidad: desmitificación de la sanción en sede indemnizatoria", Vniversitas, n. ${ }^{\circ} 125$ (2012): 361-363.

30 Maximiliano Aramburo Calle, "Responsabilidad civil y riesgo en Colombia: apuntes para el desarrollo de la teoría del riesgo en el siglo XXI", Revista de la Facultad de Derecho UPB, n. 38 (2008): 48.

31 Solarte Rodríguez, "Reparación integral del daño", 3.

32 Calabresi, The costs of accidents, 42. 


\section{C) La función sancionatoria o punitiva}

La función sancionatoria o punitiva hace referencia a la posibilidad de que la responsabilidad civil, además de reparar el daño o prevenir su causación, sancione al responsable. Es decir, que imponga un castigo - como lo hacen el derecho penal o los diversos derechos sancionatorios- por ciertas conductas que causan daños a otros, incluso si el castigo excede la entidad del daño causado.

La función sancionatoria de la responsabilidad patrimonial está proscrita por regla general en los sistemas jurídicos de tradición civili3, y la doctrina hispana es notoriamente crítica de la posibilidad de que se admita. En palabras de Llamas:

¿No resulta evidente que la responsabilidad civil previene muy mal y castiga peor? [...] ¿No hace ya suficientes siglos que se viene atribuyendo la función punitiva a una rama del ordenamiento jurídico especializada en castigar, que por eso se llama derecho penal, y que viene sometida a unos principios que en ningún caso puede aplicar el derecho civil? ${ }^{34}$.

En contraste, el ejemplo paradigmático de la función sancionatoria en la responsabilidad civil es el de los llamados daños punitivos, adoptados principalmente en Estados Unidos. Esta figura opera como una condena pecuniaria ejemplarizante en contra de quien ha dañado de forma intencional, maliciosa o extremadamente negligente ${ }^{35}$. Según la perspectiva que se adopte, los daños punitivos pueden entenderse como una sanción por el reproche moral al responsable (carácter punitivo) o como una disuasión en contra del daño eficiente (carácter preventivo) ${ }^{36}$. Nada obsta para que comprenda ambos componentes.

A pesar del rechazo mayoritario a importar esta figura a los sistemas del derecho civil, algunos se preguntan sobre la conveniencia de considerar una función sancionatoria de la responsabilidad patrimonia ${ }^{37}$. Incluso, en la doctrina colombiana

Guido Alpa, Nuevo tratado de la responsabilidad civil (Lima: Jurista Editores, 2006), 776-777.

Llamas Pombo, “Formas de reparación del daño", 110.

Anthony Sebok, "Punitive damages in the United States", en Punitive damages: Common law and civil law perspectives, editado por Helmut Koizol y Vanessa Wilcox (Nueva York: Springer-Verlag, 2009), 155.

Thomas Calligan, "Augmented awards: The efficient evolution of punitive damages", Louisiana Law Review 5 (1990): 36-37.

Para De Ángel Yagüez, cuando el juez fija la indemnización por la causación del daño está sujeto a su apreciación personal sobre las circunstancias fácticas, la cual muy probablemente estará "influida por el juicio que moralmente le merezca el comportamiento del responsable”, Ricardo de Ángel Yagüez, Algunas previsiones sobre el futuro de la responsabilidad civil, con especial atención a la reparación del daño (Madrid: Civitas, 1995), 61. 
se ha sugerido que ya existen normas civiles que consagran sanciones por la sola conducta ilícita, aun sin la existencia de un daño, o que incorporan la gravedad de la conducta en la graduación de la consecuencia jurídica ${ }^{38}$. Rojas Quiñones, tomando impulso en estos antecedentes normativos, ha propuesto incorporar explícitamente una indemnización punitiva en Colombia, sujeta a ciertas reglas ${ }^{39}$. Hasta ahora, vale anotar, no es más que un debate doctrinal.

\section{D) La función distributiva}

Por último, se ha discutido si la responsabilidad civil puede o debe cumplir una función distributiva. Volvamos a la distinción entre justicia correctiva y justicia distributiva explicada al inicio de este artículo: la pregunta que concierne a la función distributiva es si la responsabilidad civil, además de corregir una interacción ilícita entre los asociados, se debe preocupar por la distribución preexistente: si debe intentar mejorar la distribución de recursos sociales que se tenía, no simplemente restablecerla.

La doctrina suele rechazar adjudicarle una función distributiva a la responsabilidad civil, por considerar que este sistema solamente responde a la justicia correctiva. En esta línea de argumentación, la responsabilidad civil no está instituida para distribuir recursos, sino que se limita a reaccionar ante una perturbación ilegítima ${ }^{40}$.

Dos argumentos principales sostienen esta postura. En primer lugar, se afirma que los criterios para la distribución de recursos en una sociedad democrática son del resorte del legislador, quien representa directamente a la colectividad, y no del juez. En segundo lugar, se cuestiona hasta qué punto la responsabilidad civil, aún si lo quisiera, podría efectivamente mejorar la distribución de recursos. En efecto, cuando se ordena la reparación del daño, lo que se hace es restablecer o restituir un statu quo preexistente. En la responsabilidad civil, el que más tiene más recibe, porque le quitaron más. $Y$, de la misma forma, el que menos tiene menos ha de recibir.

Así lo ilustra Mir Puigpelat:

A mayor daño mayor, mayor indemnización, con independencia de la necesidad. De hecho, puede decirse que la cuantía de la indemnización que ofrece la responsabilidad es, en realidad, inversamente proporcional a la situación de necesidad Université Panthéon-Sorbonne, 2018). 
de la víctima: cuanto más rica sea la víctima y, por tanto, menor su necesidad, mayor es la indemnización que percibirá. Tras la entrada en funcionamiento de la responsabilidad civil, por tanto, el rico sigue siendo igualmente rico y el pobre igualmente pobre ${ }^{41}$.

Sin embargo, no es unánime la negativa a considerar una función distributiva de la responsabilidad civil.

Por una parte, algunos autores como Gardner cuestionan la distinción misma entre justicia correctiva y justicia distributiva. Cuando la responsabilidad civil decide que alguien merece determinada compensación por un daño que sufrió, necesariamente asigna recursos con base en algún criterio moral. En esa medida, "toda justicia es distributiva"42. Es más, el solo hecho de que, como lo señalábamos, la responsabilidad civil excluya la situación económica de la víctima como criterio de reparación no es un supuesto dado y menos aún inmutable. Es una decisión jurídica y política que tiene efectos distributivos.

Por otra parte, el alcance de una función distributiva no necesariamente es igual a "redistribuir" recursos económicos. Por supuesto, esta es una opción. Pero también puede estarse ante un ejercicio distributivo cuando se distribuyen derechos y deberes de indemnidad: quién debe soportar un daño o debe evitar causarlo, y por qué ${ }^{43}$. ¿Por qué un médico que actúa sin culpa en un sistema de responsabilidad objetiva debe asumir la reparación de un daño, mientras que otro médico que despliega la misma conducta bajo un régimen de responsabilidad subjetiva no habrá de responder?

Finalmente, también puede hablarse de una función distributiva de la responsabilidad civil cuando esta corrige la aleatoriedad con la que se distribuye la carga de ser víctima de un accidente ${ }^{44}$. Este es el caso, por ejemplo, de los sistemas de responsabilidad por riesgo. Cuando se ordena la reparación del daño causado por actividades peligrosas como conducir un automóvil, instalar redes eléctricas o construir edificaciones -incluso sin existir culpa-, se tiene en cuenta que la víctima sufrió un daño de manera aleatoria. Cualquier otro miembro de la sociedad era

41 Oriol Mir Puigpelat, La responsabilidad patrimonial de la administración. Hacia un nuevo sistema (Barcelona: Edisofer, 2012), 213.

42 "La justicia no es otra cosa que la virtud moral distintiva de quien se encarga de realizar la asignación, de la persona que se ocupa de determinar quién recibirá cuánto y por qué. Dado que 'distributivo' y 'asignativo' son sinónimos, es difícil resistir la idea de que toda justicia es distributiva”. John Gardner, "La justicia correctiva, corregida", en Derecho de daños, principios morales y justicia social, editado por Diego Papayannis (Madrid: Marcial Pons, 2013), 31-32.

Papayannis, "Teorías de la responsabilidad extracontractual", 11.

Barros Bourie, Tratado de responsabilidad civil extracontractual, 52. 
candidato a sufrir ese infortunio, pero solo recayó en aquella persona. La responsabilidad civil toma en cuenta este factor y distribuye - generalmente al agente o guardián de la actividad riesgosa - la carga de asumir la reparación.

\section{Los fundamentos y las funciones de la responsabilidad civil como puente con la responsabilidad del Estado}

En las secciones antecedentes se expusieron las principales teorías sobre los fundamentos y las funciones de la responsabilidad civil. Por una parte, se vio que la responsabilidad civil puede ser justificada como: (1) una expresión de principios de justicia -casi siempre, aunque no necesariamente, bajo principios de justicia correctiva - o (2) como un instrumento para reducir los costos sociales, bajo la teoría del AED. Por otra parte, se agruparon los objetivos o tareas que puede cumplir la responsabilidad civil en cuatro categorías: (1) la función reparatoria, (2) la función preventiva, (3) la función sancionatoria y (4) la función distributiva.

Preguntarse por los fundamentos y las funciones de la responsabilidad civil permite entender cómo un determinado sistema está configurado y explicar la manera en que se regula normativamente cada uno de los supuestos que pueden dar lugar - o no- a la responsabilidad y sus consecuencias.

Piénsese, por ejemplo, que como un ejercicio doctrinal acogiéramos (1) una fundamentación de la responsabilidad civil desde la justicia correctiva y (2) una prevalencia de la función reparatoria. Esta postura dogmática ilustraría, para quien la defiende, por qué y para qué tener un sistema de responsabilidad civil: porque es un imperativo moral corregir interacciones que alteren injustamente una distribución preexistente de recursos, derechos o bienes sociales, y para restablecer la situación en la que el daño no se había producido. $O$, si se le agregan otras funciones, para evitar que se produzcan daños, para sancionar a los responsables, para distribuir mejor los recursos sociales, etcétera.

En este artículo se sostiene que, por vía de los fundamentos y las funciones, es posible explorar si es justificado el tratamiento diferencial en la responsabilidad patrimonial cuando el daño es causado por un particular frente a cuando es causado por un agente del Estado. En efecto, si en ambos sistemas los fundamentos y las funciones fueran exactamente los mismos, difícilmente se justificaría una diferenciación que lleve, por ejemplo, a que un mismo hecho dañoso con las mismas consecuencias sobre la víctima sea tratado de forma diferente en uno y otro 
régimen. Si, en cambio, hay diferencias relevantes, la distinción entre la responsabilidad de los particulares y del Estado puede resultar justificada, siempre y cuando responda conscientemente a esos principios superiores que la alimentan.

En consecuencia, pasaremos a estudiar si es posible esta extensión de los fundamentos y las funciones de la responsabilidad civil a su contraparte pública, con sus argumentos y contraargumentos. Siguiendo el orden hasta ahora planteado, primero exploraremos los fundamentos para luego descender a las funciones.

\section{A) Argumentos y contraargumentos para extender los fundamentos de la responsabilidad civil a la responsabilidad del Estado}

Contemplar una unificación sustancial entre los regímenes de responsabilidad de los particulares y del Estado en Colombia pasa, necesariamente, por la vía de entender si los dos sistemas comparten los mismos fundamentos. ¿Por qué el Estado debe responder por los daños que causan sus agentes? ¿Puede justificarse de igual forma a como se fundamenta la responsabilidad civil de los particulares?

Existen similitudes evidentes entre ambos regímenes. La existencia de un daño como presupuesto base de la obligación reparatoria no ha sido cuestionada por regla general en ninguno de los dos sistemas, y ello de por sí sugiere que algún grado de similitud debe existir en sus fundamentos.

Sin embargo, las principales diferencias en su fundamentación teórica se observan cuando se sostiene, como se ha hecho en Colombia y en otros países, que la responsabilidad del Estado se fundamenta en principios del derecho público ${ }^{45}$. Bajo esta perspectiva, aun si existe alguna similitud entre los daños que causa un particular a los que causa un agente del Estado, la justificación de un sistema de responsabilidad en cabeza del órgano público -y no solo del agente que causó el daño- se ubica en los principios del derecho constitucional y del derecho administrativo.

A continuación, se relacionan algunas aproximaciones en las que se ha fundamentado la responsabilidad extracontractual del Estado desde principios del derecho público:

1. La responsabilidad del Estado, junto con el principio de legalidad, se constituye como uno de los dos principales mecanismos de control al

Para Dworkin, la distinción entre áreas del derecho como el derecho público y el derecho privado puede ser "mecánica y arbitraria", pero tiene mayor fuerza "cuando los límites entre los departamentos tradicionales del derecho investigan principios morales ampliamente reconocidos que distinguen tipos de falta o responsabilidad", Dworkin, El imperio de la justicia, 57-59. 
poder público. Y el control al poder público se entiende —desde esta postura- como la razón de ser del derecho administrativo ${ }^{46}$. Como lo expone Hauriou: "Hay dos correctivos de la prerrogativa de la administración que reclama el instinto popular, cuyo sentimiento respecto al poder público puede formularse en estos dos brocardos: que actúe, pero que obedezca la ley; que actúe, pero que pague el perjuicio" ${ }^{47}$.

2. La responsabilidad estatal es una expresión de la función del Estado de proteger la vida, honra y bienes de los ciudadanos, también materializada en la garantía constitucional de la propiedad y el deber de las autoridades públicas de proteger a los residentes, de modo que una transgresión a este deber justifica que sea el Estado quien responda ante el afectado ${ }^{48}$.

3. La responsabilidad del Estado, más concretamente, se explica por la protección que las constituciones modernas otorgan a los asociados de determinada comunidad política sobre su patrimonio. Es decir, la responsabilidad estatal es un componente de la garantía integral del patrimonio de los administrados frente a la acción pública ${ }^{49}$. Así, si en ejercicio de sus facultades o en exceso de ellas, un agente del Estado causa un perjuicio al patrimonio de alguno de sus administrados, el sistema de responsabilidad pública garantiza que le sea reintegrado.

4. La responsabilidad estatal se explica por el deber del Estado de prestar adecuadamente los servicios públicos, de modo que su desviación -la "falla del servicio" como primer título de imputación reconocido en la jurisprudencia francesa y colombiana- debe ser reconocida a favor del administrado ${ }^{50}$. Bajo una visión más contemporánea, pero en líneas similares, podría afirmarse que la responsabilidad pública es un mecanismo de garantía de los principios de la función administrativa ${ }^{51}$, previstos hoy en el artículo 209 de la Constitución colombiana.

Una de las perspectivas explicadas por Alberto Montaña Plata en Fundamentos de derecho administrativo (Bogotá: Universidad Externado de Colombia, 2010), 32-41.

Maurice Hauriou. Précis de Droit Administratif et de Droit Public Général, traducido por Juan Alfonso Santamaría y Santiago Muñoz (Madrid: IEA, 1993).

Consejo de Estado, Sala de lo Contencioso Administrativo, Sección Tercera. Sentencias de 14 de noviembre de 1967 (Exp. 414) y 20 de septiembre del 2007 (Exp. 16208).

García de Enterría y Fernández Rodríguez, Curso de derecho administrativo, 376.

Corte Suprema de Justicia, Sala de Casación Civil. Sentencia de 30 de junio de 1941, M. P. Arturo Tapias Piloneta.

Saavedra Becerra, De la responsabilidad patrimonial del Estado, 193. Mir Puigpelat, La responsabilidad patrimonial de la administración, 117. 
5. La responsabilidad del Estado se fundamenta en los principios constitucionales de dignidad humana, solidaridad y equidad. Es una forma de garantía de que la actividad estatal se ejerce en interés de todos y que el Estado está realmente comprometido con la tutela efectiva y material de los derechos reconocidos a favor de los administrados en la Constitución y en las leyes ${ }^{52}$.

A pesar de que las posturas doctrinales y jurisprudenciales que han sido brevemente reseñadas tienen importantes diferencias entre sí, en nuestro criterio todas vuelven -con mayor o menor intensidad - a la idea del derecho público como instrumento de control del poder. Y, más recientemente, como instrumento de realización de los derechos fundamentales y cumplimiento de los fines del Estado ${ }^{53}$. Bajo esta perspectiva, la responsabilidad del Estado se explica en la medida en que pone límites a la actividad de las autoridades públicas y moldea la conducta del Estado hacia una más alineada con las normas superiores que están llamadas a regirla.

A primera vista, las justificaciones expuestas indicarían que no es posible extender la fundamentación teórica de la responsabilidad civil a la responsabilidad del Estado. La distancia parece enorme: no se está hablando simplemente de un sistema relacional entre dos sujetos (dañador y perjudicado), sino de todo un andamiaje institucional para perseguir fines superiores como es la protección misma de los ciudadanos frente a los aparatos poderosos y coercitivos que son los Estados modernos.

No obstante, la distancia no necesariamente es tan grande. Puede que el derecho público, como un todo, tenga como fin último el control del poder. Pero, como podría extraerse de la frase de Hauriou, tal fin se refleja de distintas maneras en cada institución que lo compone. Una cosa es el control del poder por vía del principio de legalidad como límite de la actuación administrativa, y otra es que cuando un agente estatal cause un daño el Estado deba repararlo — si este daño es "antijurídico", que no ilegal o ilícito ${ }^{54}$. enero del 2013 (Exp. 23924) y 12 de junio del 2014 (Exp. 27759).

53 Eberhard Schmidt-Assman, La teoría general del derecho administrativo como sistema, traducido por Javier Barnés et al. (Madrid: Marcial Pons, 2003), 1-50.

54 En los regímenes de responsabilidad del Estado se exige cada vez menos que el daño sea ilícito y por el contrario debe ser antijurídico, es decir, aquel que la víctima no está obligada a soportar. Algunos, no obstante, han criticado la circularidad del concepto de antijuridicidad, como por ejemplo Tamayo: "La pregunta del desesperado es esta: ¿y cuándo la víctima tiene obligación de soportarlo? Y la respuesta de la nueva doctrina de la reconquista española a dicha pregunta es esta: cuando el 
En esta medida, los fundamentos de la responsabilidad civil pueden ayudar a entender por qué una de las vías de control del poder estatal es, precisamente, su responsabilidad por los daños causados:

1. En algunas ocasiones, desde una perspectiva de la justicia correctiva, el Consejo de Estado ha sostenido que la responsabilidad estatal se justifica a partir del principio alterum non laedere, o de no dañar injustificadamente a los otros ${ }^{55}$. El Estado no puede dañar a menos de que exista una justificación para hacerlo, porque alteraría ilegítimamente el estado de cosas de los ciudadanos que le han concedido poder en su nombre. La relación entre los ciudadanos y el Estado también es bilateral, y el imperativo moral de que el perjudicado sea restituido a la situación preexistente no cambia dependiendo de quién cause el daño.

2. En otros escenarios, el propio Consejo de Estado ha dado a entender que la responsabilidad del Estado se nutre de la justicia distributiva. Piénsese, por ejemplo, en la figura del daño especial: este daño se considera causado cuando, aun sin estar ante una actuación ilícita de la autoridad pública, se considera que el particular afectado sufrió un perjuicio excesivo frente al que la distribución normal de las cargas públicas le exige soportar. Lo que hace el juez en este escenario es redistribuir la carga del daño, ya no al particular que lo sufrió, sino al Estado responsable ${ }^{56}$. Y al asignarlo al Estado - conformado por todos los asociados-, distribuye entre todos sus miembros la carga de asumir ese daño que recayó en alguno de ellos por circunstancias fuera de su control.

3. Bajo una perspectiva instrumental -aunque no propiamente del AEDse ha propuesto que la responsabilidad del Estado funciona como un sistema de incentivos para evitar que las dependencias estatales causen daños. En principio, la responsabilidad pública no produce incentivos económicos al agente, porque no lo obliga a responder directamente

Estado tiene el derecho de causarlo. Y el ignorante con sentido común insiste: ¿y cuándo el Estado tiene el derecho de causarlo? Y es allí donde la doctrina española que pregona la nueva teoría no se explaya para delimitar el concepto. Hay una especie de silencio sospechoso de inconsistencia", Javier Tamayo Jaramillo, La responsabilidad del Estado. El daño antijurídico, el riesgo excepcional y las actividades peligrosas (Bogotá: Temis, 1997), 31. marzo del 2015 (Exp. 37726). septiembre de 1994 (Exp. 8577); 3 de mayo del 2007 (Exp. 16696) y 30 de abril del 2014 (Exp. 28214), entre otras. 
por el daño causado ${ }^{57}$. Y, por esta razón, el AED es escéptico sobre su efectividad. Sin embargo, la responsabilidad pública retira recursos de las dependencias del Estado que han causado daños, creando así incentivos políticos para no causarlos en el futuro, si dichas dependencias quieren mostrar a los electores resultados positivos con los recursos que les han sido asignados ${ }^{58}$.

Si bien los principios del derecho público pueden justificar, de manera general, por qué la responsabilidad del Estado se instituye como un mecanismo de control del poder público -e incluso de realización de los fines del Estado-, los fundamentos de la responsabilidad civil explican por qué controlar al Estado de esta manera, entre otras varias. Nótese que, cuando un agente estatal causa un daño a un particular, la respuesta no se agota simplemente con revisar si se cumplió o no con el principio de legalidad, o con determinar si el agente debe ser retirado del servicio. En estos escenarios, la situación de la víctima es igual de importante —o más-, y la explicación de este fenómeno se podrá encontrar en alguna de las teorías sobre los fundamentos de la responsabilidad civil.

Como asunto final de esta sección, vale la pena señalar que los fundamentos de la responsabilidad civil también han sido utilizados por algunos sectores de la doctrina para cuestionar la existencia misma de los sistemas de responsabilidad del Estado. Por ejemplo, desde la justicia correctiva se ha criticado que, si el Estado es quien responde por los daños causados por el agente, se anula el imperativo moral que exige que sea el dañador quien restituya los efectos de la interacción injustificada $^{59}$. A su vez, para el AED no es del todo convincente la existencia de un sistema de responsabilidad pública porque resulta difícil establecer un conjunto de incentivos idóneo para controlar la actividad estatal. En efecto, el Estado no maneja "su propio dinero" como un privado, por lo que la responsabilidad pública no reduce la probabilidad de que el aparato estatal cause daños, ya que los funcionarios no sienten sus consecuencias como sí lo haría un privado ${ }^{60}$.

Excepción hecha de la acción de repetición (en Colombia, art. 90 inc. 2, C. Pol.), pero en este caso el incentivo sería generado precisamente por la acción de repetición y no por la responsabilidad pública como tal. costs", University of Chicago Law Review 67, n. 2 (2000): 408.

60 Jeremy Rabkin, "Where the lines have held: Tort claims against the federal government", Proceedings of the Academy of Political Science 37, n. ${ }^{\circ} 1$ (1988): 119. 
En nuestro criterio, estas críticas refuerzan y no contradicen la hipótesis de que los fundamentos de la responsabilidad civil permiten explicar la responsabilidad del Estado. Estudiar los fundamentos de un sistema de responsabilidad no quiere decir estar de acuerdo con su configuración particular ni con su existencia misma. Por el contrario, lo que revelan las críticas antes enunciadas es que los fundamentos de la responsabilidad civil son un insumo determinante para dilucidar por qué debe existir —o no- la responsabilidad pública. E, incluso, si desde la perspectiva teórica que se adopte no es posible justificar la existencia de la responsabilidad del Estado como sistema autónomo a la responsabilidad civil, una respuesta coherente podría ser la de proponer eliminar dicho sistema especial por no tener un fundamento persuasivo en el sistema jurídico.

Naturalmente, no acogemos una propuesta abolicionista como la mencionada, porque ya se han expuesto con suficiencia múltiples justificaciones para que el Estado responda por los daños causados por sus agentes. Pero sí permite sugerir que la responsabilidad pública se explica y se entiende mejor cuando se estudia en conjunto con su contraparte privada.

\section{B) Argumentos y contraargumentos para extender las funciones de la responsabilidad civil a la responsabilidad del Estado}

En estrecha línea con los fundamentos, las funciones de la responsabilidad civil son un insumo determinante para establecer si se justifica tratar en forma unificada o distinta los daños causados por particulares y por agentes del Estado. Puede ser incluso más claro: si se sabe para qué el sistema debe responder ante un daño -qué objetivos debería perseguir-, el hecho de que las consecuencias sean iguales o distintas puede determinar si verdaderamente uno y otro régimen están cumpliendo con su cometido.

Cada una de las funciones de la responsabilidad civil exploradas en este artículo tiene particularidades de interés para la responsabilidad del Estado. A nuestro juicio, son más los puntos en común que las diferencias, como vamos a ver:

1. La función reparatoria ha sido ampliamente reconocida en la responsabilidad del Estado, al igual que en la responsabilidad civil. En efecto, la jurisprudencia colombiana ha afirmado reiteradamente la prevalencia del principio de reparación integral en la responsabilidad del Estado. Incluso, los usos múltiples que la jurisprudencia de la Corte Suprema de Justicia le ha dado a este principio - reconocer nuevas tipologías 
de daño extrapatrimonial y aumentar, reducir o limitar la cuantía de la indemnización de los daños inmateriales - se replican en forma muy similar en la jurisprudencia de la Sección Tercera del Consejo de Estado ${ }^{61}$. Con un uso adicional: adoptar nuevas consecuencias de la responsabilidad bajo el concepto de medidas de reparación ${ }^{62}$. Hasta ahora no parece haberse sostenido con éxito ninguna diferencia entre la necesidad de reparar integralmente el daño que causa un particular y el que causa un agente del Estado.

2. La función preventiva también aparece en las discusiones sobre la responsabilidad extracontractual del Estado. Ya se vio cómo desde el AED se cuestiona si la responsabilidad pública puede tener realmente un carácter preventivo ${ }^{63}$. Pero este cuestionamiento ha tenido al menos dos respuestas: (1) quienes consideran que la responsabilidad pública puede disuadir a las autoridades de cometer daños que luego puedan costarles políticamente ${ }^{64}$ y (2) quienes entienden que la responsabilidad del Estado comprende una llamada función de control, muy similar a la llamada función preventiva. Esta función de control implica que la responsabilidad pública tiene un rol de "configurar, modelar y modular la actuación administrativa, que enseña a la Administración cómo debe actuar y cómo no, [...] y ayuda, en última instancia, a evitar los daños derivados de la acción pública"65.

3. La función sancionatoria tiene un tratamiento doctrinal similar entre la responsabilidad civil y la responsabilidad del Estado: se suele negar su aplicación en ambas. La diferencia quizás radique en que, en el ámbito de la responsabilidad del Estado, el rechazo a la función punitiva es aún

Véase Consejo de Estado, Sala de lo Contencioso Administrativo, Sección Tercera. Sentencias de 14 de febrero de 1992 (Exp. 6477); 25 de septiembre de 1997 (Exp. 10285); 6 de septiembre del 2001 (Exp. 13232); 4 de mayo del 2011 (Exp. 17396); 14 de septiembre del 2011 (Exp. 19031 y 38222 ); 18 de marzo del 2010 (Exp. 32651); 9 de junio del 2010 (Exp. 19849); 25 de septiembre del 2013 (Exp. 36460) y 28 de agosto del 2014 (Exp. 27709, 31172, 31149, 31170 y 32988 ).

Este uso se ha visto por ahora en algunas sentencias de la Sección Tercera del Consejo de Estado, con influjo de la Corte Interamericana de Derechos Humanos y la Ley 965 del 2005 (de "Justicia y paz"). Estas nuevas consecuencias de la responsabilidad incluyen medidas de rehabilitación, restitución y reparación simbólica, entre otras. Véase Consejo de Estado, Sala de lo Contencioso Administrativo, Sección Tercera. Sentencias de 20 de febrero del 2008 (Exp. 16996); 4 de mayo del 2011 (Exp. 19355); 9 de mayo del 2011 (Exp. 36912); 25 de mayo del 2011 (Exp. 15838); 29 de marzo del 2012 (Exp. 20816); 9 de julio del 2014 (Exp. 44333).

Rabkin, "Where the lines have held", 119.

Rosenthal, "A theory of governmental damages liability", 833.

Luis Martín Rebollo parafraseado por Mir Puigpelat en La responsabilidad patrimonial de la administración, 116-118. 
mayor que en la responsabilidad de los particulares ${ }^{66}$. En general, no parecería tener sentido "castigar" al Estado, porque este, al final, somos todos los ciudadanos: ¿qué se gana castigándonos a todos por la conducta de un funcionario? Incluso, en los Estados Unidos los llamados daños punitivos están expresamente excluidos respecto a la responsabilidad estatal ${ }^{67}$. En tal medida, el ámbito "sancionatorio" de la responsabilidad pública por ahora parece limitado a la acción de repetición, consecuencia secundaria de los daños causados por el dolo o la culpa grave de un agente del Estado, pero en todo caso no a la responsabilidad estatal misma.

4. Finalmente, la función distributiva desempeña un papel central en la responsabilidad del Estado. En líneas anteriores se explicó cómo las consideraciones distributivas son las que sostienen regímenes como la responsabilidad por riesgo y la responsabilidad por daño especial. La corrección de aleatoriedad con la que se distribuye la carga de ser víctima de un daño y el establecimiento de derechos y deberes de indemnidad derivados de ciertas actividades estatales son una expresión de la función distributiva en la responsabilidad del Estado.

Incluso, a la responsabilidad estatal se han trasladado varias críticas contra la función distributiva. Entre ellas se resaltan dos: (1) al igual que la responsabilidad civil —o incluso más - la responsabilidad estatal tiene efectos que desde una óptica distributiva serían injustos, porque asigna a particulares (los demandantes) recursos públicos que podrían perseguir fines sociales más generales como salud, educación y trabajo ${ }^{68}$, y (2) si se quiere que el derecho de daños cumpla algún fin distributivo, sería la seguridad social — bajo algún esquema de fondos públicos - la indicada para cumplir dichas funciones ${ }^{69}$, nuevamente para garantizar una distribución más justa entre todos los asociados. 1997), 117. sabilidad patrimonial del Estado, 162. Mir Puigpelat, La responsabilidad patrimonial de la administración, 212-215. 
Los párrafos anteriores sugieren que la responsabilidad del Estado persigue los mismos fines que la responsabilidad civil, aunque con algunos matices relevantes. Lo que en una es reparar en la otra también lo es. Lo que en una es disuadir en la otra es controlar. Lo que en una se distribuye en la otra también, aunque con mayor intensidad. Y ésta es una lección a obtener de la anterior exposición de funciones: entre la responsabilidad privada y pública hay diferencias, pero parecen ser diferencias de grado.

\section{Conclusiones}

¿Qué implica todo lo anterior frente al objetivo de entender las similitudes y diferencias entre la responsabilidad civil y la responsabilidad del Estado? ¿La responsabilidad civil puede seguir cumpliendo el papel omnicomprensivo —sobre particulares y sobre el Estado- que alguna vez cumplió?

De este artículo se desprende que el puente existe. Una justificación de la responsabilidad estatal que no tenga en cuenta el influjo de fundamentaciones teóricas sobre la responsabilidad civil difícilmente puede explicar por qué -entre las diversas formas de controlar la actuación del Estado- este debe responder cuando uno de sus agentes causa un daño. Ya sea a partir de principios de justicia o desde una perspectiva instrumental, la relación entre víctima y responsable requiere establecer un vínculo jurídico entre ellos que solo la teoría general de la responsabilidad civil ha logrado articular convincentemente.

Y, aunque desde el inicio de este artículo se advirtió que no se resolvería si la responsabilidad civil y la responsabilidad del Estado deben unificarse en Colombia, es posible dejar planteada una aproximación inicial a esta discusión.

La revisión de las teorías sobre los fundamentos y las funciones en la responsabilidad privada y pública sugieren que, cuando se justifica alguna distinción entre ambos regímenes, aquella parece recaer en el carácter público —-social, colectivo, compartido- de los recursos que sufragan la reparación del perjuicio causado por el agente estatal. En efecto, las críticas esgrimidas contra la responsabilidad del Estado tanto desde la justicia correctiva como desde el AED sostienen que no es justo o no es eficiente trasladar a toda la colectividad el daño causado por un solo agente estatal. Cuando se evalúan los efectos distributivos de la responsabilidad del Estado, cobra especial relevancia el hecho de que los recursos sean públicos: 
son recursos que provienen de todos los asociados y que, en caso de no utilizarse para reparar, podrían destinarse a otros fines sociales importantes.

Lo anterior sugiere que la responsabilidad estatal no es únicamente bilateral, ya que en una de las partes convergen múltiples intereses, incluso contrapuestos entre sí. En consecuencia, las decisiones que involucran a la parte pública necesariamente impactan la distribución de los recursos sociales — que es, según se indicó, la esencia de la justicia distributiva-. No sucede igual con la responsabilidad civil.

Sin embargo, si no se adopta una postura abolicionista de la responsabilidad del Estado, como no se adopta en este artículo y no se ha adoptado en Colombia, la incidencia de tales diferencias disminuye considerablemente. Una vez se reconoce que el Estado debe responder por los daños ocasionados por sus agentes, la justificación de ambos sistemas resulta notablemente similar. El grado de la diferencia, que ha empezado a esbozarse en los párrafos anteriores, es el que podrá ser objeto de discusiones adicionales.

En conclusión, hasta ahora, la teoría parece favorecer más un matrimonio con discusiones que un divorcio.

\section{Referencias}

Alpa, Guido. Nuevo tratado de la responsabilidad civil. Lima: Jurista Editores, 2006.

Aramburo Calle, Maximiliano. "Responsabilidad civil y riesgo en Colombia: apuntes para el desarrollo de la teoría del riesgo en el siglo XXI". Revista de la Facultad de Derecho UPB, n. 38 (2008): 15-51.

Barros Bourie, Enrique. Tratado de responsabilidad civil extracontractual. Santiago: Editorial Jurídica de Chile, 2007.

Botero Aristizábal, Luis Felipe. "El concepto de daño". En Derecho de las obligaciones, tomo III, coordinado por Marcela Castro de Cifuentes, 4384. Bogotá: Temis; Universidad de los Andes, 2018.

Calabresi, Guido. The costs of accidents: A legal and economic analysis. New Haven: Yale University Press, 1970.

Calligan, Thomas. "Augmented awards: The efficient evolution of punitive damages". Louisiana Law Review 5 (1990): 6-86. 
Coleman, Jules, Scott Hershovitz y Gabriel Mendlow. "Theories of the common law of torts". En The Stanford encyclopedia of philosophy, editado por Edward N. Zalta, 2015.

Consejo de Estado, Sala de lo Contencioso Administrativo, Sección Tercera. Sentencia de 14 de noviembre de 1967. Exp. 414. M. P. Gabriel Rojas Arbeláez.

Consejo de Estado, Sala de lo Contencioso Administrativo, Sección Tercera. Sentencia de 14 de febrero de 1992. Exp. 6477. M. P. Julio César Uribe Acosta.

Consejo de Estado, Sala de lo Contencioso Administrativo, Sección Tercera. Sentencia de 23 de septiembre de 1994. Exp. 8577. M. P. Julio César Uribe Acosta.

Consejo de Estado, Sala de lo Contencioso Administrativo, Sección Tercera. Sentencia de 25 de septiembre de 1997. Exp. 10285. M. P. Ricardo Hoyos Duque.

Consejo de Estado, Sala de lo Contencioso Administrativo, Sección Tercera. Sentencia de 6 de septiembre del 2001. Exp. 13232. M. P. Alier Eduardo Hernández Enríquez.

Consejo de Estado, Sala de lo Contencioso Administrativo, Sección Tercera. Sentencia de 3 de mayo del 2007. Exp. 16696. M. P. Enrique Gil Botero.

Consejo de Estado, Sala de lo Contencioso Administrativo, Sección Tercera. Sentencia de 20 de septiembre del 2007. Exp. 16208. M. P. Mauricio Fajardo Gómez.

Consejo de Estado, Sala de lo Contencioso Administrativo, Sección Tercera. Sentencia de 20 de febrero del 2008. Exp. 16996. M. P. Enrique Gil Botero.

Consejo de Estado, Sala de lo Contencioso Administrativo, Sección Tercera. Sentencia de 18 de marzo del 2010. Exp. 32651. M. P. Enrique Gil Botero.

Consejo de Estado, Sala de lo Contencioso Administrativo, Sección Tercera. Sentencia de 9 de junio del 2010. Exp. 19849. M. P. Enrique Gil Botero.

Consejo de Estado, Sala de lo Contencioso Administrativo, Sección Tercera. Sentencia de 4 de mayo del 2011. Exp. 19355. M. P. Enrique Gil Botero.

Consejo de Estado, Sala de lo Contencioso Administrativo, Sección Tercera. Sentencia de 9 de mayo del 2011. Exp. 36912. M. P. Enrique Gil Botero.

Consejo de Estado, Sala de lo Contencioso Administrativo, Sección Tercera. Sentencia de 25 de mayo del 2011. Exp. 15838. M. P. Jaime Orlando Santofimio Gamboa. 
Consejo de Estado, Sala de lo Contencioso Administrativo, Sección Tercera. Sentencia de 14 de septiembre del 2011. Exp. 19031. M. P. Enrique Gil Botero.

Consejo de Estado, Sala de lo Contencioso Administrativo, Sección Tercera. Sentencia de 14 de septiembre del 2011. Exp. 38222. M. P. Enrique Gil Botero.

Consejo de Estado, Sala de lo Contencioso Administrativo, Sección Tercera. Sentencia de 29 de marzo del 2012. Exp. 20816. M. P. Danilo Rojas Betancourth.

Consejo de Estado, Sala de lo Contencioso Administrativo, Sección Tercera. Sentencia de 30 de enero del 2013. Exp. 23924. M. P. Jaime Orlando Santofimio Gamboa.

Consejo de Estado, Sala de lo Contencioso Administrativo, Sección Tercera. Sentencia de 25 de septiembre del 2013. Exp. 36460. M. P. Enrique Gil Botero.

Consejo de Estado, Sala de lo Contencioso Administrativo, Sección Tercera. Sentencia de 12 de junio del 2014. Exp. 27759. M. P. Jaime Orlando Santofimio Gamboa.

Consejo de Estado, Sala de lo Contencioso Administrativo, Sección Tercera. Sentencia de 9 de julio del 2014. Exp. 44333. M. P. Enrique Gil Botero.

Consejo de Estado, Sala de lo Contencioso Administrativo, Sección Tercera. Sentencia de 25 de marzo del 2015. Exp. 37726. M. P. Hernán Andrade Rincón.

Consejo de Estado, Sala de lo Contencioso Administrativo, Sección Tercera. Sentencia de 30 de abril del 2014. Exp. 28214. M. P. Danilo Rojas Betancourth.

Consejo de Estado, Sala de lo Contencioso Administrativo, Sección Tercera. Sentencias de 28 de agosto del 2014. (Unificación). Exp. 27709, $31172,31149,31170$ y 32988.

Consejo de Estado, Sala de lo Contencioso Administrativo, Sección Tercera. Aclaración de voto del magistrado Martín Bermúdez Muñoz a la sentencia del 18 de julio del 2019. Exp. 44572.

Consejo de Estado, Sala de lo Contencioso Administrativo, Sección Tercera. Aclaración de voto del magistrado Martín Bermúdez Muñoz a la sentencia del 20 de noviembre del 2020. Rad. 2013-00216(AG).

Corte Suprema de Justicia, Sala de Casación Civil. Sentencia de 21 de julio de 1922. G. J. XXIX, n. ${ }^{\circ}$ 1515. M. P. Tancredo Nannetti. 
Corte Suprema de Justicia, Sala de Casación Civil. Sentencia de 22 de agosto de 1924. G. J. XXXI, n. ${ }^{\circ}$ 1602. M. P. Tancredo Nannetti.

Corte Suprema de Justicia, Sala de Casación Civil. Sentencia de 25 de noviembre de 1992. n. ${ }^{\circ}$ C-478. M. P. Carlos Esteban Jaramillo Schloss.

Corte Suprema de Justicia, Sala de Casación Civil. Sentencia de 13 de mayo del 2008. Rad. 1997-09327-01. M. P. César Julio Valencia Copete.

Corte Suprema de Justicia, Sala de Casación Civil. Sentencia de 18 de septiembre del 2009. Rad. 2005-00406-01. M. P. William Namén Vargas.

Corte Suprema de Justicia, Sala de Casación Civil. Sentencia de 9 de julio del 2010. Rad. 1999-02191-01. M. P. William Namén Vargas.

Corte Suprema de Justicia, Sala de Casación Civil. Sentencia de 9 de diciembre del 2013. Rad. 2002-00099-01. M. P. Ariel Salazar Ramírez.

Corte Suprema de Justicia, Sala de Casación Civil. Sentencia de 5 de agosto del 2014. Rad. 2003-00660-01. M. P. Ariel Salazar Ramírez.

Corte Suprema de Justicia, Sala de Casación Civil. Sentencia de 17 de noviembre del 2016. Rad. 2000-00196-01. M. P. Álvaro Fernando García Restrepo.

Cuadros, Óscar Álvaro. Responsabilidad del Estado: fundamentos, aplicaciones, evolución jurisprudencial. Buenos Aires: Abeledo-Perrot, 2008.

De Ángel Yagüez, Ricardo. Algunas previsiones sobre el futuro de la responsabilidad civil, con especial atención a la reparación del daño. Madrid: Civitas, 1995.

Degeling, Simone y Kit Barker. "Designing Reparation: Lessons from Private Law". En New directions for law in Australia, editado por Ron Levy et al., 321-328. Sídney: Australia National Univeristy Press, 2017.

Díez-Picazo, Luis. Derecho de daños. Madrid: Civitas, 1999.

Dworkin, Ronald. El imperio de la justicia, traducido por Claudia Ferrari. Barcelona: Gedisa, 2008.

García de Enterría, Eduardo y Tomás Fernández Rodríguez. Curso de derecho administrativo, tomo II. Madrid: Thomson-Civitas, 2004.

García Vásquez, Diego. "La oficialización de la pena privada en Colombia”. Tesis de doctorado, Université Panthéon-Sorbonne, 2018.

Gardner, John. "La justicia correctiva, corregida". En Derecho de daños, principios morales y justicia social, editado por Diego Papayannis. Madrid: Marcial Pons, 2013. 
Hauriou, Maurice. Précis de Droit Administratif et de Droit Public Général, traducido por Juan Alfonso Santamaría y Santiago Muñoz. Madrid: IEA, 1993.

Henao Pérez, Juan Carlos. El daño. Análisis comparativo de la responsabilidad extracontractual del Estado en derecho colombiano y francés. Bogotá: Universidad Externado de Colombia, 2007.

Hirsch, Werner. Law and economics. an introductory analysis. San Diego: Academic Press, 1999.

Jaramillo Jaramillo, Carlos Ignacio. Los deberes de evitar y mitigar el daño. Funciones de la responsabilidad civil en el siglo XXI y trascendencia de la prevención. Bogotá: Pontificia Universidad Javeriana, 2013.

Levinson, Daryl. "Making government pay: Markets, politics and the allocation of constitutional costs". University of Chicago Law Review 67, n. 2 (2000): 345-420.

Llamas Pombo, Eugenio. "Formas de reparación del daño". En Realidades y tendencias del derecho en el siglo XXI, tomo IV, 57-113. Bogotá: Pontificia Universidad Javeriana, 2010.

Margaux, Yolanda y Ciro Guecha. "La responsabilidad del Estado, una obligación de indemnizar perjuicios". Revista Diálogos de Saberes, n. ${ }^{\circ} 25$ (2006): 193-210.

Mir Puigpelat, Oriol. La responsabilidad patrimonial de la administración. Hacia un nuevo sistema. Barcelona: Edisofer, 2012.

Montaña Plata, Alberto. Fundamentos de derecho administrativo. Bogotá: Universidad Externado de Colombia, 2010.

Navia Arroyo, Felipe. "Daño moral, daño fisiológico y daño a la vida de relación en Colombia". Revista de Derecho Privado Universidad Externado de Colombia, n. ${ }^{\circ} 12-13$ (2007): 211-231.

Papayannis, Diego. "Teorías de la responsabilidad extracontractual". Working Papers Universitat de Girona, n. ${ }^{\circ} 29$ (2010).

Rabkin, Jeremy. "Where the lines have held: Tort claims against the federal government". Proceedings of the Academy of Political Science 37, n. 1 (1988): 112-125.

Rojas Quiñones, Sergio. “Apología del potencial preventivo de la responsabilidad: desmitificación de la sanción en sede indemnizatoria". Vniversitas, n. ${ }^{\circ} 125$ (2012): 339-375.

Rosenthal, Lawrence. "A theory of governmental damages liability: Torts, constitutional torts and takings". University of Pennsylvania Journal of Constitutional Law 9, n. 3 (2007): 797-870. 
Saavedra Becerra, Ramiro. De la responsabilidad patrimonial del Estado, tomo I. Bogotá: Ibáñez, 2018.

Salvador Coderch, Pablo y María Teresa Castiñeira Palou. Prevenir y castigar. Madrid: Marcial Pons, 1997.

Sandoval Garrido, Diego. "Reparación integral y responsabilidad civil: el concepto de reparación integral y su vigencia en los daños extrapatrimoniales a la persona como garantía de los derechos de las víctimas". Revista de Derecho Privado Universidad Externado de Colombia, n. ${ }^{\circ} 25$ (2013): 237-273.

Schmidt-Assman, Eberhard. La teoría general del derecho administrativo como sistema, traducido por Javier Barnés et al. Madrid: Marcial Pons, 2003.

Sebok, Anthony. "Punitive damages in the United States". En Punitive damages: Common law and civil law perspectives, editado por Helmut Koizol y Vanessa Wilcox. Nueva York: Springer-Verlag, 2009.

Solarte Rodríguez, Arturo. "El principio de reparación integral del daño en el derecho contemporáneo". En Tendencias de responsabilidad civil en el siglo XXI. Bogotá: Pontificia Universidad Javeriana, 2009.

Solarte Rodríguez, Arturo. "Reparación integral del daño y restitución de los beneficios obtenidos por el civilmente responsable". IARCE (2015).

Tamayo Jaramillo, Javier. La responsabilidad del Estado. El daño antijurídico, el riesgo excepcional y las actividades peligrosas. Bogotá: Temis, 1997. 